\title{
Percutaneous radiofrequency lesions adjacent to the dorsal root ganglion alleviate spasticity and pain in children with cerebral palsy: pilot study in 17 patients
}

\author{
Georges F Vles', Johan S Vles*1, Maarten van Kleef², Jan van Zundert², Heleen M Staal², Wim E Weber', \\ Lodewijk W van Rhijn 3 , Dan Soudant ${ }^{1}$, H Kerr Graham4 and Anton J de Louw ${ }^{5}$
}

\begin{abstract}
Background: Cerebral palsy (CP) may cause severe spasticity, requiring neurosurgical procedures. The most common neurosurgical procedures are continuous infusion of intrathecal baclofen and selective dorsal rhizotomy. Both are invasive and complex procedures. We hypothesized that a percutaneous radiofrequency lesion of the dorsal root ganglion (RF-DRG) could be a simple and safe alternative treatment. We undertook a pilot study to test this hypothesis.

Methods: We performed an RF-DRG procedure in 17 consecutive CP patients with severe hip flexor/adductor spasms accompanied by pain or care-giving difficulties. Six children were systematically evaluated at baseline, and 1 month and 6 months after treatment by means of the Modified Ashworth Scale (MAS), Gross Motor Function Measure (GMFM) and a self-made caregiver's questionnaire. Eleven subsequent children were evaluated using a Visual Analogue Scale (VAS) for spasticity, pain and ease of care.
\end{abstract}

Results: A total of 19 RF-DRG treatments were performed in 17 patients. We found a small improvement in muscle tone measured by MAS, but no effect on the GMFM scale. Despite this, the caregivers of these six treated children unanimously stated that the quality of life of their children had indeed improved after the RF-DRG. In the subsequent 11 children we found improvements in all VAS scores, in a range comparable to the conventional treatment options.

Conclusion: RF-DRG is a promising new treatment option for severe spasticity in CP patients, and its definitive effectiveness remains to be defined in a randomised controlled trial.

\section{Background}

Cerebral palsy $(\mathrm{CP})$ is a central nervous system deficit resulting from a non-progressive lesion in the developing brain. Although these brain lesions are static, the movement disorders that arise are not unchanging and are characterised by atypical muscle tone, posture and movement [1]. The spastic motor type is the most common form of $\mathrm{CP}$ and its conventional therapeutic management may include splinting/casting, physiotherapy, occupational therapy, oral spasmolytics and anti-dystonic drugs, Botulinum Toxin-A (BTX-A) injections, orthopaedic procedures, and neurosurgical procedures. The most com-

\footnotetext{
* Correspondence: jsh.vles@mumc.nl
}

1 Neurology, Maastricht University Medical Centre, Maastricht, the Netherlands Full list of author information is available at the end of the article

() 2010 Vles et al; licensee BioMed Central Ltd. This is an Open Access article distributed under the terms of the Creative Commons AtC medium, provided the original work is properly cited. mon neurosurgical procedures are continuous infusion of intrathecal Baclofen (ITB) and selective dorsal rhizotomy (SDR). Since its first description by Foerster in 1913, SDR has been modified by various researchers and has become a standard neurosurgical procedure to treat spasticity in CP patients [2-5]. However, as multiple-level laminectomies at the L1-S1 level are often required, the procedure is invasive and can lead to complications as transient urinary incontinence, chronic low back pain and spinal deformity [6-9]. Considerable cooperation of the patient is required to successfully complete the postoperative rehabilitation program.

An alternative for the SDR is a radiofrequency lesion of the dorsal root ganglion (RF-DRG), which has been used to treat chronic pain for over 30 years [10]. The RF-DRG 
is a simple and safe treatment with little side effects [1113]. In the 1980's several authors reported that the same procedure might be used to treat adult patients with spasticity $[14,15]$. More recently, we were able to show that an RF-DRG alleviates hip flexor spasms in $2 \mathrm{CP}$ patients [16]. CP patients can also suffer from severe pain through spasticity, bone deformities or joint subluxation, especially hip displacement and dislocation $[17,18]$, which may lead, through an enhanced processing of afferent information within the spinal cord, to secondary pain [19].

We thus hypothesized that an RF-DRG may alleviate spasticity and pain in CP patients, and we tested this hypothesis in a pilot study of 17 patients.

\section{Methods}

Children with spasticity from $\mathrm{CP}$ were seen by a multidisciplinary spasticity management team (child neurologist, orthopaedic surgeon, and physician assistant child neurology) in the Maastricht University Medical Centre(JV, LvR, HS, DS). Individual treatment goals were determined after a careful assessment of the aetiology, functional ability and associated impairments as a result of the spasticity. The RF-DRG treatment was considered in children with severe hip flexor/adductor spasms accompanied by pain or care giving difficulties. The procedure was approved by the Institutional Review Board of the Maastricht University Medical Centre, according to Dutch governmental regulations and informed consent from the caregivers was obtained for each patient.

A total of 17 children were treated with RF-DRG (tables 1 and 2). The severity of CP was based on the Gross Motor Function Classification System (GMFCS) for CP $[20,21]$. Hip(sub)luxation was classified according to the morphological hip classification system proposed by Robin et al [22].

Six children (group A) were systematically evaluated at baseline, and 1 month and 6 months after treatment (table 1, table 3). In this group all assessments were performed by a physical therapist. The Modified Ashworth Scale (MAS) was used for the assessment of changes in muscle tone [23]. In the MAS the muscle tone is scored on a 6 point scale, in which "0" represents no hypertonia or no increase of muscle tone and "4" represents severe hypertonia and severe stiffness of the extremities. In each patient hip flexion and adduction, knee flexion and extension and dorsal and plantar flexion in the ankle were tested bilaterally. Functional improvement was assessed using the Gross Motor Function Measure (GMFM), a widely used scale consisting of 5 different locomotor domains to evaluate treatment of spasticity in children with CP [24-26]. Furthermore, we developed a more extensive questionnaire for caregivers. Besides items on pain, several items of daily activities of life, like dressing, undressing and bathing, were investigated. Data of the 6 systematically evaluated children were statistically analyzed using a students T-test and a Wilcoxon signed rank test. A p value of $<0.05$ was considered to be statistically significant. All data are represented as means and standard error of means (SEM).

The following 11 children (group B) were evaluated at 6 weeks and 3 months using a Visual Analogue Scale (VAS), which was used to measure the severity of the individually formulated problems. We changed the evaluation methods, as we were not able to detect the kind of change that the caregivers unanimously did notice. Furthermore, we learned from literature that the MAS and the GMFM are not indicated to measure changes in these severely handicapped children [27-29]. Instead we used a VAS, which is a valid pain-rating instrument [30]. The VAS used in pain assessment is a straight $10 \mathrm{~cm}$ horizontal line with anchor points of no pain (score 0 ) and unbearable pain (score 10). For our study we changed the anchor points into very satisfied (score 0 ) and very dissatisfied (score 10) to use the VAS uniformly for individually defined problems [[31,32], figure 1]. A VAS score for spasticity, pain, and ease of care was given by the caregivers, since the majority of the $\mathrm{CP}$ patients were severely mentally handicapped. Usually the patient and his/her caregiver(s) are the best judges of the severity of the impairments accompanying spasticity, as they are the only people who can assess its impact on the daily life of the patient [33]. Caregivers of children with profound impairments note changes in function far more accurately than staff workers [34].

\section{RF-DRG procedure}

All patients were treated in our outpatient clinic, and RFDRG was performed as described [12,13,35]. Under general anaesthesia, the patients were placed in prone position on an operating table. The level to be treated was based on clinical symptoms; afterwards stimulation was used to verify these levels.

The procedure was performed in tunnel vision, a technique for entering the electrode in the direct vision of the $\mathrm{X}$-rays. Therefore, the $\mathrm{C}$-arm (Ziehm electronics) was adjusted in such a way that the X-rays ran parallel to the end plates of the relevant level. Thereafter, the $\mathrm{C}$-arm was rotated until the processus spinosus projected over the contralateral facet column. With the C-arm in this projection, the injection point was found by projecting a metal ruler over the lateral part of the foramen intervertebrale.

A 10-cm long, 22-G needle SMK-5 mm tip was inserted locally in the direction of the X-rays. Thereafter, the direction was corrected in such a way that the needle was being projected as a point on the screen. The direction of the radiation beam was now modified to a profile (lateral) view, and the needle was inserted until the point was 
Table 1: Summary of 6 patients (Group A) treated with RF-DRG and evaluated systematically

\begin{tabular}{|c|c|c|c|c|c|c|c|c|c|c|c|c|c|c|c|c|c|c|c|}
\hline & \multirow[t]{2}{*}{$m / f$} & \multirow[t]{2}{*}{ Age (yr) } & \multirow[t]{2}{*}{ Aetiology } & \multirow{2}{*}{$\begin{array}{l}\text { GMFCS } \\
\text { score }\end{array}$} & \multirow{2}{*}{$\begin{array}{c}\text { RF-DRG- } \\
\text { left }\end{array}$} & \multirow[t]{2}{*}{ RF-DRG-right } & \multicolumn{3}{|c|}{ Indication } & \multicolumn{3}{|c|}{ Improvement 4w } & \multirow{2}{*}{$\begin{array}{c}\text { Side- } \\
\text { Effects 4w }\end{array}$} & \multicolumn{3}{|c|}{ Improvement 6m } & \multirow{2}{*}{$\begin{array}{c}\text { Side- } \\
\text { Effects } 6 \mathrm{~m}\end{array}$} & \multicolumn{2}{|c|}{ Hip morphology } \\
\hline & & & & & & & spast & pain & care & spast & pain & care & & spast & pain & care & & Left & Right \\
\hline 1 & $f$ & 6 & Asphyxia & V & L1-2 & L1-2 & $\cdot$ & & $\cdot$ & + & & & no & + & & & no & IV & III \\
\hline 2 & $f$ & 12 & Trauma & v & L1-4 & L1-4 & $\cdot$ & $\cdot$ & $\cdot$ & + & + & + & no & + & + & + & no & III & I \\
\hline 3 & $f$ & 16 & Premature & v & - & L1-3 & & $\cdot$ & $\cdot$ & & + & + & no & & + & + & no & II & V \\
\hline 4 & $f$ & 11 & Asphyxia & V & L2-4 & L2-4 & $\cdot$ & & & + & & & no & + & & & no & ॥ & IV \\
\hline 5 & $\mathrm{~m}$ & 7 & Premature & v & L1-2 & - & & $\cdot$ & & & - & & yes & & + & & no & V & III \\
\hline 6 & $f$ & 14 & Asphyxia & V & - & L1-3 & . & . & . & + & + & + & no & + & + & + & no & III & $\mathrm{V}$ \\
\hline
\end{tabular}

m: male; f: female; yr: years; GMFCS: Gross Motor Function Classification System; spast: spasticity

$\because$ indication

Improvement: +/-: summary of improvement/worsening measured by the self-made questionnaire

$4 \mathrm{w}: 4$ weeks; $6 \mathrm{~m}: 6$ months 
Table 2: Summary of 11 patients (Group B) treated with RF-DRG and evaluated by VAS.

\begin{tabular}{|c|c|c|c|c|c|c|c|c|c|c|c|c|c|c|c|c|c|c|}
\hline & \multirow[t]{2}{*}{$\mathrm{m} / \mathrm{f}$} & \multirow[t]{2}{*}{ Age (yr) } & \multirow[t]{2}{*}{ SCPE } & \multirow{2}{*}{$\begin{array}{l}\text { GMFCS } \\
\text { Score }\end{array}$} & \multirow[t]{2}{*}{ RF-DRG-left } & \multirow[t]{2}{*}{ RF-DRG-right } & \multicolumn{3}{|c|}{ Indication } & \multirow[t]{2}{*}{ VAS pre } & \multicolumn{3}{|c|}{ Improvement } & \multirow[t]{2}{*}{ VAS post } & \multirow[t]{2}{*}{$\Delta$-VAS } & \multirow[t]{2}{*}{ Side-effects } & \multicolumn{2}{|c|}{ Hip morphology } \\
\hline & & & & & & & spast & pain & care & & spast & pain & care & & & & left & right \\
\hline 1 & $f$ & 18 & 2 & v & L1-3 & - & & $\cdot$ & & 8 & & + & & 2 & 6 & no & III & v \\
\hline 2 & $f$ & 22 & 2 & v & L1-4 & - & $\cdot$ & $\cdot$ & & 10 & + & + & & 1.5 & 8.5 & no & ns & ns \\
\hline 3 & $f$ & 10 & 2 & v & L1-2 & L1-2 & - & - & & 10 & + & & & 8 & 2 & no & $\mathrm{V}$ & III \\
\hline 4 & $\mathrm{~m}$ & 16 & 2 & v & L1-3 & - & & - & & 7 & & + & & 3 & 4 & no & $\|$ & $\mathrm{v}$ \\
\hline 5 & $\mathrm{~m}$ & 16 & 2 & V & L1-4 & - & - & $\cdot$ & & 8.2 & & + & & 1.6 & 6.6 & no & IV & v \\
\hline 6 & $\mathrm{~m}$ & 7 & 2 & V & - & L1-3 & $\cdot$ & & & ns & & & & ns & & yes & 0 & III \\
\hline 7 & $\mathrm{~m}$ & 5 & 2 & v & L1-3 & L1-3 & $\cdot$ & & - & ns & & & + & ns & & no & IV & IV \\
\hline 8 & $f$ & 11 & 2 & V & L1-2 & - & & - & & 6 & & + & & 2 & 4 & no & $*$ & $\|$ \\
\hline \multirow[t]{3}{*}{9} & $f$ & 10 & 2 & V & L1-2 & - & - & - & - & 8 & & + & + & 5.5 & 2.5 & no & 1 & 1 \\
\hline & $f$ & 12 & 2 & V & L1-2 & - & . & . & . & 8 & & + & + & 5 & 3 & no & 1 & I \\
\hline & $f$ & 14 & 2 & V & L1-2 & - & - & - & - & 10 & & & & 10 & 0 & no & 1 & 1 \\
\hline 10 & $\mathrm{~m}$ & 5 & 2 & V & L1-4 & L1-4 & - & & . & ns & + & & & ns & & no & II & $\mathrm{V}$ \\
\hline 11 & $f$ & 16 & 2 & V & L1-4 & L1-4 & - & - & - & 8.7 & + & + & + & 3.1 & 5.6 & no & ns & ns \\
\hline
\end{tabular}

m: male; f: female; yr: years; SCPE: surveillance for cerebral palsy in Europe classification: (1) unilateral; (2) bilateral

GMFCS: Gross Motor Function Classification System * Osteomyelitis; ns: not scored;

: indication

+: domain in which the improvement measured by VAS was noted 
Table 3: Modified Ashworth Scale scores of the first 6 patients: pre-operative, post-operative 4 weeks and 6 months.

\begin{tabular}{|c|c|c|c|c|c|c|c|c|c|c|c|c|c|}
\hline \multirow[b]{2}{*}{ Pt } & & \multicolumn{2}{|c|}{ Hipflexion } & \multicolumn{2}{|c|}{ Hip adduction } & \multicolumn{2}{|c|}{ Knee flexion } & \multicolumn{2}{|c|}{ Knee extension } & \multicolumn{2}{|c|}{ Ankle dorsal flexion } & \multicolumn{2}{|c|}{ Ankle plantar flexion } \\
\hline & & $\mathbf{L}$ & $\mathbf{R}$ & $\mathbf{L}$ & $\mathbf{R}$ & $\mathbf{L}$ & $\mathbf{R}$ & $\mathbf{L}$ & $\mathbf{R}$ & $\mathbf{L}$ & $\mathbf{R}$ & $\mathbf{L}$ & $\mathbf{R}$ \\
\hline \multirow[t]{3}{*}{1} & Pre & $1+$ & $1+$ & 1 & 2 & 1 & 2 & 0 & 0 & 3 & 3 & 0 & 0 \\
\hline & Post4w & 1 & 1 & 0 & 0 & 1 & 1 & 0 & 0 & 2 & 2 & 0 & 0 \\
\hline & Post6m & 1 & 0 & 1 & 1 & 1 & 0 & 0 & 0 & 3 & 2 & 0 & 0 \\
\hline \multirow[t]{3}{*}{2} & Pre & 0 & 0 & 1 & 3 & 0 & 0 & 1 & 1 & 3 & 3 & 0 & 0 \\
\hline & Post4w & 0 & 0 & 1 & 1 & 0 & 0 & 1 & 1 & 1 & 1 & 0 & 0 \\
\hline & Post6m & 0 & 0 & 1 & 1 & 0 & 0 & 0 & 0 & 1 & 1 & 0 & 0 \\
\hline \multirow[t]{3}{*}{3} & Pre & 0 & 1 & $1+$ & 2 & 1 & 1 & 2 & 2 & 3 & 3 & 0 & 1 \\
\hline & Post4w & 0 & $1+$ & $1+$ & 1 & $1+$ & 1 & 2 & $1+$ & 2 & 2 & 0 & 0 \\
\hline & Post6m & 2 & 1 & 2 & 1 & 2 & 1 & 0 & 0 & 2 & 2 & 0 & 0 \\
\hline \multirow[t]{3}{*}{4} & Pre & 0 & 0 & 1 & 1 & $1+$ & $1+$ & 3 & 3 & 0 & 0 & 1 & 1 \\
\hline & Post4w & 0 & 0 & 0 & 0 & 2 & 2 & 0 & 0 & 1 & 0 & 0 & 0 \\
\hline & Post6m & 1 & 1 & 0 & 0 & 2 & 2 & 0 & 0 & 1 & 1 & 0 & 0 \\
\hline \multirow[t]{3}{*}{5} & Pre & 2 & 0 & 0 & 1 & 0 & $1+$ & 2 & 2 & 2 & 2 & $1+$ & $1+$ \\
\hline & Post4w & 1 & 1 & 0 & 1 & 1 & 2 & 1 & 4 & 1 & 1 & 2 & 3 \\
\hline & Post6m & 2 & 0 & 0 & 0 & 2 & 4 & 0 & 0 & 2 & 3 & 0 & 0 \\
\hline \multirow[t]{3}{*}{6} & Pre & 3 & 3 & 4 & 4 & 4 & 4 & 4 & 4 & 4 & 3 & 4 & 3 \\
\hline & Post4w & 0 & 0 & 1 & 0 & 3 & 1 & 2 & 3 & 2 & $1+$ & 2 & 2 \\
\hline & Post6m & 3 & 3 & 4 & 3 & 3 & 3 & 0 & 0 & 4 & 4 & 4 & 4 \\
\hline \multirow[t]{3}{*}{ Mean } & Pre & 1 & 0.83 & 1.33 & 2.17 & 1.17 & 1.5 & 2 & 2 & 2.5 & 2.33 & 1 & 1 \\
\hline & Post4w & 0.33 & 0.5 & 0.75 & 0.5 & 1.33 & 1.17 & 1 & 1.5 & 1.5 & 1.17 & 1.67 & 0.83 \\
\hline & Post6m & 1.5 & 0.83 & 1.33 & 1.0 & 1.67 & 1.67 & 0.17 & 0 & 2.17 & 2.17 & 0.67 & 0.67 \\
\hline
\end{tabular}

located in the craniodorsal part of the foramen intervertebrale (Figure 2a).

In an AP view, the course of a small amount of contrast agent was followed with "real-time imaging"; it should spread out laterocaudally along the spinal nerve (Figure $2 \mathrm{~b})$. The stylet was removed and exchanged for the radio frequent probe. After checking the impedance (an indicator for the type of tissue next to the cannula tip), electrical stimulation was started at a rate of $2 \mathrm{~Hz}$ and the corresponding muscles were observed for contractions. At 2 $\mathrm{Hz}$ stimulation motor contractions should be observed in the area of the relevant muscles at a threshold between 0.4-0.8 Volts. $1 \mathrm{ml}$ local anaesthetic solution (bupivacain $0.5 \%)$ was injected and radio frequent current was then led through the electrode in order to increase the temperature to $67^{\circ} \mathrm{C}$ for 60 seconds. Total operating time, including anaesthesia, was about 45 minutes. All patients were discharged from the clinic the same day after full recovery from the anaesthesia.

\section{Results}

A total of 19 RF-DRG treatments were performed in 17 patients. One patient received three interventions, as the effects gradually wore off. A summary of the clinical data, including treated levels and outcome measures, are given in table 1 (group A: 6 patients) and table 2 (group B: 11 patients). In 2 patients a transient increase in pain after the RF-DRG procedure was noted, and 1 patient was successfully treated with Gabapentine for 4 weeks. No further side effects (e.g. dysaesthesia or excessive weakness in the treated limbs) were reported. No significant differences were observed between the different lumbar levels for both the impedance and the stimulation threshold.

\section{Group A}

In the first six systematically evaluated children (table 1) an improvement in muscle tone after RF-DRG was detected on both the short (4 weeks) and long (6 months) term using the MAS. Especially the right hip adductors showed improvement on the MAS which went from 2.2 +/- 0.5 before RF-DRG to $0.5+/$ - 0.2 four weeks after RFDRG and $1.0+/-0.4$ six months after RF-DRG (table 3). Due to the small sample size, no comment on the lack of significance of a null result can be given.

Using the GMFM no improvement was observed after RF-DRG treatment. At baseline a mean total score 


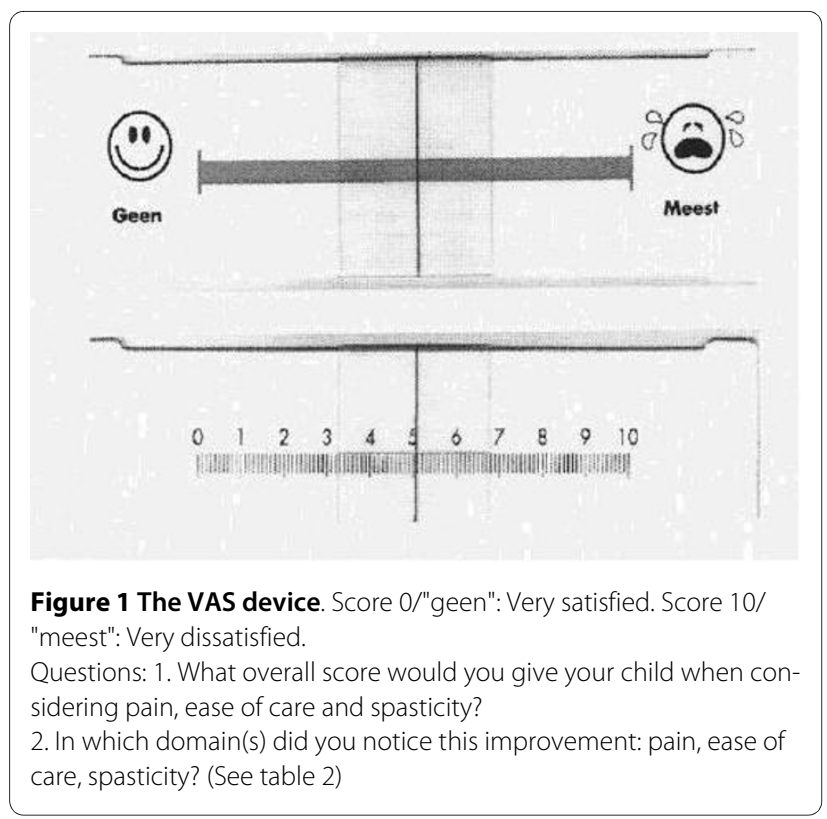

including all 5 domains of $17.2 \%+/-6$ was found. After 4 weeks the score was $17.3 \%+/-7$ and after 6 months the score was $16.2 \%+/-6$.

Using the caregiver's questionnaire, an improvement in ease and quality of care and pain was detected. Although statistically not significant, in four patients pain in the lower extremities decreased, at both 4 weeks and 6 months. In one patient there was no change in pain and in another patient pain increased at 4 weeks but decreased at 6 months when compared to the baseline.

\section{Group B}

Because of the abovementioned results we switched to a VAS to evaluate the initiated treatment in the subsequent patients. This score was available in 8 out of the 11 patients. The missing values are due to the fact that some caregivers did not feel comfortable judging their own child in a numerical way. During outpatient follow up, the
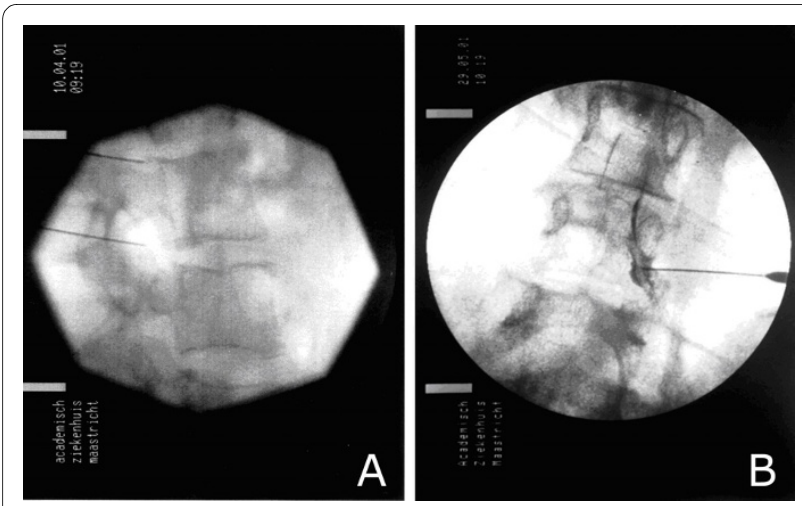

Figure 2 Photomicrograph showing the position of an RF electrode a: lateral view and b: anterior-posterior view after injection of Omnipaque. evaluation of the VAS scores showed improvement in most of the defined goals in most children (table 2). Most parents reported that the positive effects of the RF-DRG lasted at least 6-9 months.

In one patient (no. 9), the VAS score showed no change after the third procedure. Her flexor spasms were then successfully treated with Botulinum Toxin-A injections in the iliopsoas and adductor muscles (Dysport, Ipsen).

\section{Discussion}

To test our hypothesis that RF-DRG may be a serious treatment option for severe spasticity in children with $\mathrm{CP}$, we undertook a pilot study in 17 patients. Our primary treatment goal was improvement of well-being and ease of care of CP patients with severe hip flexor/adductor spasms and pain. Our first 6 consecutively treated patients (Group A) were evaluated at baseline, 1 month after treatment and 6 months after treatment with the GMFM and the MAS. We found a small improvement in muscle tone by the MAS, but no effect on the GMFM scale. Despite this, the caregivers of these six treated children unanimously stated that the quality of life of their children had indeed improved after the RF-DRG (data not shown, summary represented by $+/$ - in table 1 ). This disagreement between the MAS and the judgement of the caregivers highlights the difficulties measuring change in these severely handicapped children. The MAS as a method for the evaluation of the treatment of spasticity in children with CP has been disputed before, although in adult populations the reliability of the MAS has been demonstrated [27]. In a study in children with moderate to severe spasticity, a wide variability in test-retest results was reported for the MAS [28]. The assumption that the MAS purely measures spasticity is not entirely right. The MAS measures a broader set of neural and musculoskeletal factors of non-velocity-dependent hypertonia in addition to spasticity itself [29].

Furthermore, we added up the MAS scores of different muscles to produce a summed Ashworth score, in order to compare with most previous studies. However, this might be methodologically incorrect because the Ashworth score is an ordinal level measure [36].

For the next 11 patients we thus changed our evaluating system: instead of the MAS and the GMFM, we asked the caregivers to give a VAS score for spasticity, pain and ease of care at different time points. Using this outcome measure we were able to show a significant improvement in spasticity, pain and ease of care after an RF-DRG procedure, lasting up to 9 months. In two patients we found a transient increase in pain, for which 1 patient received Gabapentine for 4 weeks. This is a known transient procedure related event [37]. Although this was not a controlled study, the amount of improvement in VAS scores is in the same range as in conventional treatments, e.g. 
intrathecal baclofen (ITB) and SDR [31,38]. RF-DRG is thus a promising new treatment option for severe spasticity in CP patients, and its definitive effectiveness remains to be defined in a randomised controlled trial. It is less invasive and has probably less side effects than ITB and SDR, but its main disadvantage in this patient population is, of course, the temporary character of its effects. In this regard RF-DRG resembles BTX-A treatment, but its main advantage over this therapeutic option is its strong painreducing effect. Theoretically, repetitive RF-DRG's may lead to dysesthesias and causalgias, but we have not seen this in the one patient we treated three times [35]. To prevent this possible side effect, more definitive effects of RF-DRG might perhaps be achieved with higher radiofrequency currents and temperatures during the procedure.

Our pilot study does highlight the methodological problem of evaluating treatment effects in children with $\mathrm{CP}$. As we were not able to conduct an extensive battery of clinical tests in our pilot study, we had to select a few outcome measures. Using the MAS and the GMFM, we were not able to detect any beneficial effects, which is in line with other studies [33]. We had to resort to a VAS to find improvements in the condition of treated patients. In retrospect we should also have included the Pediatric Evaluation of Disability Inventory (PEDI), which is a generic standardised instrument used by the multidisciplinary team for evaluating functional performance, programme monitoring, documentation of functional development and clinical decision-making $[31,38,39]$.

The exact mechanism of action of an RF-DRG lesion remains unknown. We recently reported an increase of proliferation inside the dorsal root ganglion after RFDRG adjacent to the ganglion without signs of neural tissue damage (e.g. necrosis) inside the ganglion [40]. For years, the only mode of action of a radiofrequency lesion was thought to be through nerve damage due to thermocoagulation [41]. Recent experiments with pulsed radiofrequency treatment (a high-frequency current delivered in bursts of $20 \mathrm{~ms}$ followed by a silent period of $480 \mathrm{~ms}$, during which the generated heat is washed out) suggest that thermocoagulation is not the only mode of action $[41,42]$. A late and temperature-independent increase in the expression of the immediate early $c$-fos gene within the rat spinal cord was found after exposure of the cervical dorsal root ganglion to continuous radiofrequency $\left(67^{\circ} \mathrm{C}\right)$ and pulsed radiofrequency current [43]. In one model of spasticity, the locomotor abnormalities are thought to be the result of hyperexcitability of spinal interneurons involved in the spinal stretch reflex [44]. Reduction of spinal input through de-afferentation is then the basic mechanism of RF-DRG.

\section{Conclusion}

Our pilot study on RF-DRG in 17 CP patients with severe hip flexor/adductor spasms and pain shows that it may improve spasticity, pain, and ease of care, with a duration of up to 9 months. As the amount of improvement is in the same range as in conventional treatments, RF-DRG is thus a promising new treatment option for severe spasticity in CP patients, and its definitive effectiveness remains to be defined in a randomised controlled trial. The main advantages are the less invasive character of RF-DRG compared to the SDR with the potential benefit of a shorter hospitalisation period, and its clear pain-reducing effect.

\section{Competing interests \\ The authors declare that they have no competing interests.}

\section{Authors' contributions}

JV originated the idea, is a member of the multi-disciplinary working group and together with LR and HS selected the patients. HS and LR are also members of the multi-disciplinary working group and together with GV they scored hip classification (inter-observer agreement with each other). MK and JZ performed the procedure. DS is the supervisor of the multi-disciplinary working group and provided the date for GV which he analysed together with AL. GV wrote the article under supervision of $A L, W W$ and JV. MK en JV participated in writing the methods-sections of the article. AL, HS, KG and WW have revised the manuscript critically for important intellectual content. JV is the final supervisor of the study and manuscript.

All authors read and approved the final manuscript.

\section{Acknowledgements}

No special acknowledgements required.

\section{Author Details}

'Neurology, Maastricht University Medical Centre, Maastricht, the Netherlands, ${ }^{2}$ Anesthesiology, Maastricht University Medical Centre, Maastricht, the Netherlands, ${ }^{3}$ Orthopaedic surgery, Maastricht University Medical Centre, Maastricht, the Netherlands, ${ }^{4}$ Orthopaedic Surgery, Royal Children's Hospital, Melbourne, Australia and ${ }^{5}$ Epilepsy Centre Kempenhaeghe, Heeze, the Netherlands

Received: 2 March 2010 Accepted: 22 June 2010

Published: 22 June 2010

References

1. Krigger KW: Cerebral palsy: an overview. American family physician 2006, 73(1):91-100.

2. Farmer JP, Sabbagh AJ: Selective dorsal rhizotomies in the treatment of spasticity related to cerebral palsy. Childs Nerv Syst 2007, 23(9):991-1002.

3. Foerster $\mathrm{O}$ : On the indications and results of the excision of posterior spinal roots in men. Surg Gynecol Obstet 1913, 16:463-474.

4. Langerak NG, Lamberts RP, Fieggen AG, Peter JC, van der Merwe L, Peacock WJ, Vaughan CL: A prospective gait analysis study in patients with diplegic cerebral palsy 20 years after selective dorsal rhizotomy. $J$ Neurosurg Pediatr 2008, 1(3):180-186.

5. Steinbok P: Selective dorsal rhizotomy for spastic cerebral palsy: a review. Childs Nerv Syst 2007, 23(9):981-990.

6. Johnson MB, Goldstein L, Thomas SS, Piatt J, Aiona M, Sussman M: Spinal deformity after selective dorsal rhizotomy in ambulatory patients with cerebral palsy. Journal of pediatric orthopedics 2004, 24(5):529-536.

7. Spiegel DA, Loder RT, Alley KA, Rowley S, Gutknecht S, Smith-Wright DL, Dunn ME: Spinal deformity following selective dorsal rhizotomy. Journal of pediatric orthopedics 2004, 24(1):30-36.

8. Steinbok P, Hicdonmez T, Sawatzky B, Beauchamp R, Wickenheiser D: Spinal deformities after selective dorsal rhizotomy for spastic cerebral palsy. Journal of neurosurgery 2005, 102(4 Suppl):363-373.

9. Turi $M$, Kalen $\mathrm{V}$ : The risk of spinal deformity after selective dorsal rhizotomy. Journal of pediatric orthopedics 2000, 20(1):104-107.

10. Uematsu S, Udvarhelyi GB, Benson DW, Siebens AA: Percutaneous radiofrequency rhizotomy. Surg Neurol 1974, 2(5):319-325. 
11. Segnarbieux F, Frerebeau P: The different (open surgical, percutaneous thermal, and intrathecal chemical) rhizotomies for the treatment of spasticity. In Neurosurgery for spasticity: a multidisciplinary approach Edited by: M S, Abbott RYK. New York: Springer Verlag; 1991:133-139.

12. van Kleef $\mathrm{M}$ : Radiofrequency lesions of the dorsal root ganglion in the treatment of spinal pain. Maastricht, Maastricht University; 1996.

13. van Kleef M: Radiofrequency lesions of the dorsal root ganglion in the treatment of spinal pain. Maastricht University. 1996.

14. Herz DA, Parsons KC, Pearl L: Percutaneous radiofrequency foramenal rhizotomies. Spine (Phila Pa 1976) 1983, 8(7):729-732.

15. Kasdon DL, Lathi ES: A prospective study of radiofrequency rhizotomy in the treatment of posttraumatic spasticity. Neurosurgery 1984 15(4):526-529.

16. Vles J, van Kleef M, Sleypen F, Bulstra S, Szpak K, Luijckx GJ, Beuls E, Sluyter $M E$, Troost J: Radiofrequency lesions of the dorsal root ganglion in the treatment of hip flexor spasm: a report of two cases. Eur J Paediatr Neurol 1997, 1(4):123-126.

17. Bagg MR, Farber J, Miller F: Long-term follow-up of hip subluxation in cerebral palsy patients. Journal of pediatric orthopedics 1993, 13(1):32-36.

18. Schwartz L, Engel JM, Jensen MP: Pain in persons with cerebral palsy. Arch Phys Med Rehabil 1999, 80(10):1243-1246.

19. Mayer $\mathrm{NH}$ : Clinicophysiologic concepts of spasticity and motor dysfunction in adults with an upper motoneuron lesion. Muscle Nerve Supp/ 1997, 6:S1-13.

20. Palisano R, Rosenbaum P, Walter S, Russell D, Wood E, Galuppi B: Development and reliability of a system to classify gross motor function in children with cerebral palsy. Developmental medicine and child neurology 1997, 39(4):214-223.

21. Wood E, Rosenbaum P: The gross motor function classification system for cerebral palsy: a study of reliability and stability over time. Developmental medicine and child neurology 2000, 42(5):292-296.

22. Robin J, Graham HK, Baker R, Selber P, Simpson P, Symons S, Thomason P: A classification system for hip disease in cerebral palsy. Developmental medicine and child neurology 2009, 51(3):183-192.

23. Bohannon RW, Smith MB: Interrater reliability of a modified Ashworth scale of muscle spasticity. Phys Ther 1987, 67(2):206-207.

24. Kirschner JHF, Mall F, Linder M, Stein S, Michaels U, Korinthenberg R: Gross Motor Function Measure for therapy evaluation in children treated with botulinum toxin A. Dev Med Child Neurol 1 1998, 78(Suppl:I1):

25. Russell D, Rosenbaum P, Gowland C, Hardy S, Lane M, Plews N, McGavin H, Cadman D, Jarvis S: Manual for the Gross Motor Function Measure. Hamilton ON, Canada: McMaster University; 1993.

26. Russell DJ, Rosenbaum PL, Cadman DT, Gowland C, Hardy S, Jarvis S: The gross motor function measure: a means to evaluate the effects of physical therapy. Developmental medicine and child neurology 1989 31(3):341-352.

27. Gregson JM, Leathley M, Moore AP, Sharma AK, Smith TL, Watkins CL: Reliability of the Tone Assessment Scale and the Modified Ashworth Scale as clinical tools for assessing poststroke spasticity. Arch Phys Med Rehabil 1999, 80:1013-16.

28. Fosang AL, Galea MP, McCoy AT, Reddihough DS, Story I: Measures of muscle and joint performance in the lower limb of children with cerebral palsy. Dev Med Child Neurol 2003, 45:664-70.

29. Report of the Quality Standards Subcomittee of the American Academy Of Neurology and the Practice Committee of the Child Neurology Society: Practice Parameter: Pharmacologic treatment of spasticity in children and adolescents with cerebral palsy (an evidence-based review). Neurology 2010, 74:336-43.

30. Stinson JN, Kavanagh T, Yamada J, Gill N, Stevens B: Systematic review of the psychometric properties, interpretability and feasibility of selfreport pain intensity measures for use in clinical trials in children and adolescents. Pain 2006, 125(1-2):143-157.

31. Hoving MA, van Raak EP, Spincemaille GH, Palmans $L$, Becher JG, Vles JS: Efficacy of intrathecal baclofen therapy in children with intractable spastic cerebral palsy: a randomised controlled trial. Eur J Paediatr Neurol 2009, 13(3):240-246.

32. Vles GF, de Louw AJ, Speth $L A$, van Rhijn $L W$, Janssen-Potten $Y$ J, Hendriksen JG, Vles JS: Visual Analogue Scale to score the effects of Botulinum Toxin A treatment in children with cerebral palsy in daily clinical practice. Eur J Paediatr Neurol 2008, 12(3):231-238.
33. Hanna K, Rodger S: Towards family-centered practice in paediatric occupational therapy: a review of the literature on parent-therapist collaboration. Aust Occup Ther J 2002, 49:4-24.

34. White-Koning M, Arnaud C, Bourdet-Loubere S, Bazex H, Colver A, Grandjean H: Subjective quality of life in children with intellectual impairment--how can it be assessed? Developmental medicine and child neurology 2005, 47(4):281-285.

35. van Kleef M, Barendse GA, Dingemans WA, Wingen C, Lousberg $R$, de Lange S, Sluijter ME: Effects of producing a radiofrequency lesion adjacent to the dorsal root ganglion in patients with thoracic segmental pain. The Clinical journal of pain 1995, 11(4):325-332

36. Pandyan AD, Johnson GR, Price Cl, Curles RH, Barnes MP, Rodgers H: A review of the properties and limitations of the Ashworth and modified Ashworth Scales as measures of spasticity. Clin Rehabil 1999, 13:373-83.

37. Van Kleef M, Liem L, Lousberg R, Barendse G, Kessels F, Sluijter M: Radiofrequency lesion adjacent to the dorsal root ganglion for cervicobrachial pain: a retrospective double blind randomized study. Neurosurgery 1996, 38:1127-32

38. Nordmark E, Josenby AL, Lagergren J, Andersson G, Stromblad LG, Westbom L: Long-term outcomes five years after selective dorsal rhizotomy. BMC pediatrics 2008, 8:54.

39. Haley S, Coster W, Ludlow L, Haltiwanger J, Andrellos P: Peadiatric Evaluation Disability Inventory (PEDI), Version 1,0. Boston, MA, USA New England Medical Centre Hospitals, Inc; 1992.

40. de Louw AJ, Vles HS, Freling G, Herpers MJ, Arends JW, Kleef M: The morphological effects of a radio frequency lesion adjacent to the dorsal root ganglion (RF-DRG)--an experimental study in the goat. Eur J Pain 2001, 5(2):169-174.

41. Sluijter M, Racz G: Technical aspects of radiofrequency. Pain Pract 2002, 2(3): 195-200.

42. van Zundert JLI, de Louw AJA, Jansen J, Kessels F, Patijn J, van Kleef M: Percutaneous pulsed radiofrequency treatment of the cervical dorsal root ganglion in the treatment of chronic cervical pain syndromes: a clinical audit. Neuromodulation 2003, 6(1):6-14.

43. Van Zundert J, de Louw AJ, Joosten EA, Kessels AG, Honig W, Dederen PJ, Veening JG, Vles JS, van Kleef M: Pulsed and continuous radiofrequency current adjacent to the cervical dorsal root ganglion of the rat induces late cellular activity in the dorsal horn. Anesthesiology 2005, 102(1):125-131

44. Young RR: Spasticity: a review. Neurology 1994, 44(11 Suppl 9):S12-20.

\section{Pre-publication history}

The pre-publication history for this paper can be accessed here: http://www.biomedcentral.com/1471-2377/10/52/prepub

doi: $10.1186 / 1471-2377-10-52$

Cite this article as: Vles et al., Percutaneous radiofrequency lesions adjacent to the dorsal root ganglion alleviate spasticity and pain in children with cerebral palsy: pilot study in 17 patients BMC Neurology 2010, 10:52

\section{Submit your next manuscript to BioMed Central and take full advantage of:}

- Convenient online submission

- Thorough peer review

- No space constraints or color figure charges

- Immediate publication on acceptance

- Inclusion in PubMed, CAS, Scopus and Google Scholar

- Research which is freely available for redistribution 